\title{
WestVirginiaUniversity
}

THE RESEARCH REPOSITORY @ WVU

Graduate Theses, Dissertations, and Problem Reports

2013

\section{Representation of Missing Children in National Television News}

\author{
Clara Simmons \\ West Virginia University
}

Follow this and additional works at: https://researchrepository.wvu.edu/etd

\section{Recommended Citation}

Simmons, Clara, "Representation of Missing Children in National Television News" (2013). Graduate Theses, Dissertations, and Problem Reports. 338.

https://researchrepository.wvu.edu/etd/338

This Thesis is protected by copyright and/or related rights. It has been brought to you by the The Research Repository @ WVU with permission from the rights-holder(s). You are free to use this Thesis in any way that is permitted by the copyright and related rights legislation that applies to your use. For other uses you must obtain permission from the rights-holder(s) directly, unless additional rights are indicated by a Creative Commons license in the record and/ or on the work itself. This Thesis has been accepted for inclusion in WVU Graduate Theses, Dissertations, and Problem Reports collection by an authorized administrator of The Research Repository @ WVU. For more information, please contact researchrepository@mail.wvu.edu. 
Representation of Missing Children in National Television News

\title{
Clara Simmons
}

\author{
Thesis submitted to the \\ Eberly College of Arts and Sciences \\ at West Virginia University \\ in partial fulfillment of the requirements \\ for the degree of
}

\author{
Master of Arts \\ in \\ Applied Social Research
}

Joshua Woods, Ph.D., Chair

Lisa Dilks, Ph.D.

James Nolan, Ph.D.

Department of Sociology and Anthropology

Morgantown, WV

2013

Keywords: missing child; race; gender; kidnapping; abduction; runaway 


\section{ABSTRACT \\ Representation of Missing Children in National Television News}

\section{Clara Simmons}

This study examines how closely representations of missing children in television news reflect missing children statistics from "official" sources. The methodology used in this study was a content analysis of five national television news stations from 1987-2011 using the Vanderbilt Television News Archive. News segments were coded for race, gender, age, the situation of the disappearance, and the relationship of the victim to the offender. These proportions were then compared to the proportions provided by three official data sources: two from the Federal Bureau of Investigation (FBI), and one from the Office of Juvenile Justice and Delinquency Prevention (OJJDP). Some of the key findings are that: 1) kidnapping cases were over-represented when compared to the NISMART; 2) cases involving strangers as suspects were over-represented when compared to the NISMART; 3) African-American children were under-represented in the media when compared to all three comparison sources; 4) no conclusions could be made for gender because of conflicting results between comparison data sources; 5) FOX News differed from other news stations (ABC, CBS, CNN, and $\mathrm{NBC}$ ) in their coverage for certain analyses; and 6) the news stations, excluding FOX news, shifted their coverage for certain variables across time. 


\section{TABLE OF CONTENTS}

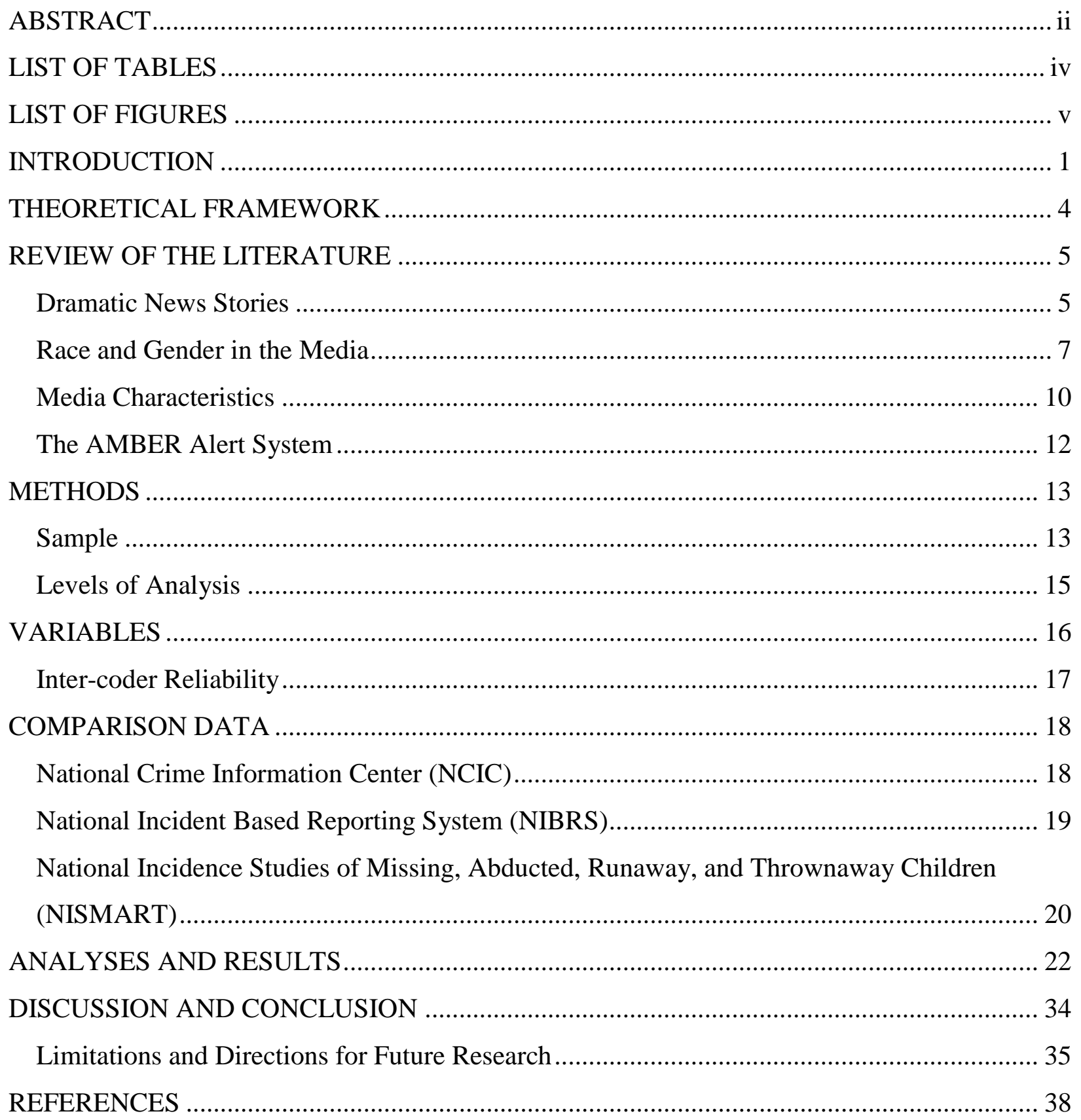




\section{LIST OF TABLES}

Table 1. Comparisons of Proportions by Unit of Analysis ................................................. 23

Table 2. Comparisons of Proportions by Station Groups ...................................................... 27

Table 3. Comparisons of Proportions by Time Period ...................................................... 30 


\section{LIST OF FIGURES}

Figure 1. Total Segments per Station in Original Population: Pre- and Post-AMBER Alert....... 32 


\section{INTRODUCTION}

Take a moment to think about what comes to mind when you hear the phrase "missing child". Personally, I tend to think about specific cases, such as JonBenét Ramsey, Adam Walsh, Natalee Holloway, and Caylee Anthony, just to name a few. If you came up with a list of the top 10 names that came to mind first, what do you think would be the similarities between these cases, and what would be the differences? What do you think would be the breakdown of race and gender? For me personally, the names that come to mind the easiest tend to be white girls.

According to FBI data, in 2012 a total of 497,327 children under the age of 18 were reported missing. However, we do not hear about all of those children, so what determines which cases appear in the media, and how much coverage they receive? This study will look at this issue more closely by analyzing missing children stories in the media and comparing them to national statistics to see if the media reflect those statistics accurately. If there is a misrepresentation in the media, this study will also attempt to explain why that might occur.

There is limited literature on the topic of bias in the media representation of missing children cases. Some articles focus on missing children stories in general and attempt to explain why those stories become so prominent in the media (Fritz and Altheide 1987). Theories on moral panic (Kellner 1981) help shed light on that phenomenon, but do not delve deeper into the details of the cases. Other studies focus on the consequences of media stories of missing children, especially in regard to policy and legislation change (Griffin and Miller 2008), by looking at specific programs such as the AMBER alert system that was developed in response to the growing missing children problem and named after a specific case.

There is one study, however, that does examine broadcast media stories about missing children to determine the discrepancies of coverage based on race and gender. Min and Feaster 
(2010) conducted a content analysis of missing children cases from five major broadcast news stations from 2005-2007 and coded for gender, race, and the situation of the disappearance. They then compared their proportions to the FBI's statistics of children reported missing for the same time span. They found that African-Americans and females were underrepresented in the media compared to the proportions reported by the FBI.

One of the major goals of this study is to replicate Min and Feaster's (2010) study to establish the reliability of their methods and analyses. To replicate their study, I will use the same sampling strategy, variable coding, and archive database and news stations to conduct a content analysis of missing children stories in national television news. I will then compare the race and gender data from the media sample to the National Crime Information Center's Missing Persons File summary tables for 2007-2010 ${ }^{1}$.

While one goal of this research is to replicate Min and Feaster's (2010) study, this research will also expand the previous study in several ways, by: 1) expanding the literature review and theoretical background; 2) using multiple levels of analysis; 3) using a larger sample size; 4) expanding the time period to 1987-2011 (one aspect of this addition will be comparing stories before and after the implementation of the national AMBER Alert system in 1996); and 5) using multiple sources of "official" comparison data.

One important relevance of this study is the issue of what some call social justice (Min and Feaster 2010). Receiving media attention can have certain benefits, and if a group receives more than others, then they would receive an advantage over those not receiving as much coverage. One study examined the influence of the show America's Most Wanted and

\footnotetext{
${ }^{1}$ The FBI's website currently has the NCIC Missing Persons Files tables for the years 2007-2012. However, the year s 2011 and 2012 was not available when the analyses were conducted, so this study only uses the NCIC data from 2007-2010.
} 
determined that the appearance of a fugitive on the show greatly increased the likelihood of them being apprehended, and also shortened the amount of time that it took police to find them again (Miles 2005). I believe this trend would be the same for missing persons as it is for missing criminals, where more media coverage devoted to finding the person would increase the chances of finding them and decrease the amount of time it takes to find them.

This means that a missing child that receives more media coverage has a distinct advantage because the chances of them being recovered are increased. Therefore, those children that do not receive as much (or any) media coverage are not only victims of their disappearance, but also victims of a social injustice. Media outlets should be aware of any biases in their coverage so that they can attempt to be more equal and fair in their coverage of missing children cases.

Another relevance of this study deals with public perceptions of the missing children problem. The media can be a way for activists, politicians, and special interest groups to spread their message and gain support for a goal, whether it be changes in policy and legislation or simply raising awareness (Best 1990). It is important for these people and organizations that the media accurately portray their cause and persuade people to support them.

It is also important for news viewers to receive accurate information. Many news stories about crime also involve some sort of explanation of how viewers can protect themselves from that type of situation. However, if the media portrayal of an issue is distorted, the public may be receiving false or incomplete information. In terms of the missing children problem, many news stories talk about ways parents can keep track of their children, such as GPS trackers. However, while many stories emphasize the importance of teaching children not to go anywhere with strangers because of the fear of stranger abductions, the most common instance of child 
kidnapping happens when a noncustodial parent or other relative is involved. So it's important to understand media coverage of an issue and how accurately they portray a topic.

\section{THEORETICAL FRAMEWORK}

This leads me into the theoretical framework for this research. In a broad sense, this study approaches the topic of missing children from a constructionist perspective. The main argument of this perspective is that social problems are socially constructed. Best makes a distinction between focusing on a social condition versus a social concern (Best 1990). Instead of focusing on the existence or prevalence of a certain topic, behavior, or activity (which would be a social condition), constructionism instead focuses on the attention or public interest in that topic, behavior, or activity (which would be a social concern).

The example Best gives is child abuse. Instead of studying the prevalence of child abuse, constructionism would be more interested in how child abuse came to be framed as a social problem. For example, at one point in time, the behavior of an adult hitting a child was not considered an issue, but over time this behavior came to be constructed as a social problem, and it is now a topic that receives a lot of attention (Best 1990).

The main way that this happens is through the media, and especially television. As Best says, "While journalists invoke standards of objectivity and speak of reporting rather than persuading, every news story seeks to offer a convincing construction of reality" (1990:88). Thus, there are some characteristics of news stories that reporters and stations may focus on because of their newsworthiness and their ability to draw an audience, appeal to emotions, and convince the audience of a claim. This leads into my general research questions: How closely 
does the media's construction of the missing children problem reflect information provided by sources that national missing children statistics?

\section{REVIEW OF THE LITERATURE}

One important aspect of examining the media's construction of a topic is to understand why these stories become prevalent in the first place. Theories on moral panic and fear, along with characteristics of the media industry, help shed light on the public's fascination with missing children stories, which in turn helps us to understand how stories in the national media become biased toward certain cases over others.

\section{Dramatic News Stories}

Stories about missing children grab the attention of the media and the public for several reasons. One major characteristic about these cases is the sense of fear of crime they instill in news consumers. Glassner's (1999) book The Culture of Fear: Why Americans Are Afraid of the Wrong Things provides new and interesting insight into how the news works (either intentionally or unintentionally) to instill a "culture of fear" into the American public. He argues that misrepresentations and misused statistics are often the root of much of this fear. He also points out that even when misrepresentations are discovered, the media coverage and public panic do not go away easily. Most of the time the fear about the exaggerated issue persists, or is connected to another important but unrelated issue (Glassner 1999), causing that fear to be constantly triggered.

Of particular relevance to the current research, Glassner (1999) specifically discusses missing children stories. He argues that this issue is often blown out of proportion by using 
statistics poorly and connecting it to other moral and social issues that are not really relevant. One way that stories get blown out of proportion is the pervasiveness of certain topics and cases. For example, the cases of Elizabeth Smart and Caylee Anthony appeared in the media on a regular basis while they were missing. As Glassner says, "reporters need not scare the daylights out of us in individual stories if they run lots of stories" (1999:195). This repetitive media coverage is bound to instill a strong sense of fear in anyone who follows the news on a regular basis.

In fact, studies have shown that the amount of television watched is connected to how afraid people are of crime. For example, a study examining parents' and children's perceptions of and reactions to kidnapping stories in the news found that the more television they watched, the higher their levels of fear of child kidnapping (Wilson, Martins, and Marske 2005). While parents generally had higher levels of fear than their children, the same positive relationship between amount of television watched and level of fear existed for children as well, especially for children under the age of thirteen (Wilson et al. 2005).

Chiricos, Eschholz, and Gertz (1997) found a similar connection between watching the news and listening to the radio and the amount of fear people had about crime. After controlling for demographic characteristics such as age, race, and sex, the authors found that people who watched more television news and listened to radio news more often had higher levels of fear of crime (Chiricos et al. 1997). However, it is interesting to note that this relationship did not exist for reading the newspaper. There was no significant relationship between reading the newspaper and fear of crime, suggesting that there are certain characteristics of broadcast news that better captivate an audience and instill a sense of fear than print media. 
One characteristic of broadcast news that makes it different from print media is the limited amount of time that can be devoted to a specific story or topic. As Best explains, a news story on television has to fit an entire story into just a few minutes, and therefore "the story must be important enough and visually interesting enough to be selected over competing topics" (1990:108). One way that news stories accomplish this is by using a specific case, such as Adam Walsh, to define the issue and make it less abstract. Offering a concrete example of the missing children problem allows viewers to connect to the issue and empathize with those victims and families. In his research, Best found that "crusaders routinely used stranger-abductions—which they acknowledged to be the least common cause of missing children — as referents" which "typifies the issue" (1990:28) of the missing children problem.

Because of the affect crime stories and television have on viewers, along with the tendency of advocates to use stranger abductions to establish the importance and relevance of the missing children problem, I propose the following hypotheses:

Hypothesis 1: Kidnapping cases will be overrepresented in national news coverage compared to the proportions provided by official data sources.

Hypothesis 2: Cases that involve strangers as suspects will be overrepresented in national news coverage compared to the proportions provided by official data sources.

Race and Gender in the Media

While the media may skew their representation of missing children cases in terms of the types of disappearances and suspects they focus on, there may also be some bias based on race 
and/or gender. There have been several studies documenting different types of biases in the media, mostly focusing on race and gender. A common phenomenon that has been studied is the "Missing White Woman Syndrome", which refers to the tendency of the media to focus on stories of missing white women over men or minorities (Liebler 2010). One study involving a content analysis of articles searching for "Missing White Women Syndrome" provided insight into how the media recognizes and explains this tendency (Liebler 2010). Most of the articles in this study blamed the nature and organization of journalism for the bias toward certain demographic groups, while others suggested an unrecognized racism where predominantly white news reporters simply do not think to cover stories involving minorities (Liebler 2010).

Another important study that documents a racial bias in news stories looked at the media coverage of Hurricane Katrina (Sommers et al. 2006). Analyzing news stories for language and story angle, the authors found that the media were more likely to use derogatory and negative language and framing when describing the hurricane survivors, most of whom were AfricanAmerican. For example, instead of using the word "survivor", "refugee" was more common, which implies a feeling of second-class citizens or some other out-group (Sommers et al. 2006). In terms of story angle, most of the articles in this study focused mainly on the criminal aspect of "looting" that occurred as people tried to find resources to survive, as opposed to framing the story around the horrible conditions those people were facing and the resourcefulness and strength of will it took to survive (Sommers et al. 2006).

One interesting study, which will be the focus of my study, is a content analysis of broadcast news stations examining the racial and gender bias in news coverage of missing children stories (Min and Feaster 2010). The authors analyzed news clips from ABC, CBS, NBC, CNN, and FOX News between 2005 and 2007 that reported cases of missing children. They 
coded each story for the race and gender of the missing child and the situation of the case, such as kidnapping, death, and general missing. They then compared that data to the actual number of missing children reported to the FBI during those same years and compared the proportions of stories based on race and gender to see if the media reported missing children cases in the same pattern as reported in official statistics.

They found that "African-American missing children cases are underrepresented in national television news compared to their actual rates of incidence," confirming their expectations (Min and Feaster 2010:212). However, "female missing children were significantly underrepresented in the coverage" (2010, pp. 212) when compared to the FBI proportions, which contradicted their expectations. In line with previous research on the "Missing White Woman Syndrome" (Liebler 2010), they expected female missing children to be overrepresented in the media, which was not the case. However, this study will still expect to find an overrepresentation of female children based on previous research on the "Missing White Woman Syndrome".

Characteristics of the media industry also come into play when examining racial and gender representations in the media. As Kellner (1981) argues, the media is essentially a profitdriven, capitalistic enterprise whose main goal is to attract as many viewers as possible in order to increase advertising revenue. Thus, the media may have a tendency to target the largest demographic groups. In terms of race, White is still the largest racial group in the United States. This may lead the media to tailor its content to stories that may interest White viewers the most. Additionally, Chiricos et al. (1997) found that the largest target group specifically for prime-time television (instead of just a national population breakdown) was middle-aged White women. Based on previous research of race and gender representation in the media, as well as the media's tendency to target the largest viewing audience, I propose the following hypotheses: 
Hypothesis 3: African-American missing children will be underrepresented in national news coverage compared to the proportions provided by official data sources.

Hypothesis 4: Female missing children will be overrepresented in national news coverage compared to the proportions provided by official data sources.

\section{Media Characteristics}

Herman and Chomsky (1988) provide a conflict perspective that evaluates external factors that influence mass media and identify five major "filters" that shape news coverage: media ownership, advertising, sources of information, negative feedback, and ideology. The first filter, media ownership, refers to the size and scope of the media, including a tiered system of prestige and power among media sources and owners, and the stressors that those owners face (Herman and Chomsky 1988). The authors illustrate the extent of the influence of the media by providing figures for the substantial profits of the major media sources. A lot of the news sources, and especially those in the top tier, are very profitable corporations and are owned by wealthy and influential people. Kellner (1981) argues that network television does not fit the ideal of a public source of open communication, and is instead more of a capitalist enterprise that seeks to maximize profits from advertising. Because the news media participates in a capitalist market, it therefore operates on a profit-driven agenda, where the goal is to maximize viewership in order to make more money, which requires interesting and captivating stories to draw in viewers and consumers. This implies an inherent bias in the goals of broadcast television, which could lead to biases in the stories the stations cover. 
The main way that news media make a profit is through the second filter: advertising (Herman and Chomsky 1988). While some news outlets, mostly print sources, may charge a subscription fee for their product, most of the profit for the media comes from advertising revenue. Because of this, media that target certain demographics (i.e., people with enough interest and money to buy their product) are more likely to receive more advertising revenue. For example, focusing on audience size would most likely lead news organizations to cater to the majority group (Min and Feaster 2010). This influences the goal of the media as well as the news that is reported. Stories of interest to those majority groups will receive greater focus and priority, whereas stories that are interesting or relevant to a less wealthy demographic group will be downplayed or ignored. In the study by Chiricos et al. (1997), the demographic group that watched television news the most (and had the highest fear of crime) was middle-aged white women. Glassner (1999) would argue that in order to captivate the attention of this majority audience group, reporters will most likely focus on dramatic stories that relate or appeal to middle-aged white women the most.

The source of information filter refers to how media sources receive their daily information (Herman and Chomsky 1988). Because reporters work under a deadline, and there is a limited amount of time they can spend gathering information and stories, they tend to focus on events and places that they already know will have important news, such as press conferences for the government, law enforcement, or even businesses. Reporters also need reliable sources for facts pertaining to other stories, such as official crime data or other types of statistics. This limited repertoire of information sources influences what the media reports, and tends to favor those people and organizations with power, wealth, and/or prestige. 
The fourth influential factor, and possibly the only one that gives viewers and consumers any power, is what Herman and Chomsky call "flak" (1988), which refers to negative reactions to the media or public outcry about something the media reported or failed to report. If flak is widespread enough, it could influence legal consequences as well as financial loss. Advertisers do not want to support news outlets that are under criticism in case the negative opinion extends to their product or service. And anything that causes advertisers to withdraw financial support is extremely harmful for the media. Therefore, if media consumers, or special interest groups, seek to make changes in the media, flak is probably the best, if not only, way to do that.

The last filter that the authors discuss relates to ideology, usually of a political nature. They use the example of Anti-Communism (Herman and Chomsky 1988), but that is not as relevant in today's media. In a more general sense, ideology influences on the media could be ascribed to a conservative or Republican vs. liberal or Democrat dichotomy. For example, FOX News is perceived as being a primarily conservative news station, whereas MSNBC is seen as being more liberal (Pew Research Center 2009, 2010). Each station could be reporting on the same event or issue, and yet have very different methods, facts, and arguments. Which ideology a news station follows relates back to the very first filter: media ownership.

Research Question 1: Do FOX News and the CNN, NBC, ABC, and CBS group differ in their coverage of missing children cases?

The AMBER Alert System

The AMBER Alert Program stands for America’s Missing: Broadcast Emergency Response and is named for Amber Hagerman, who was kidnapped and murdered in 1996 
(National Center for Missing and Exploited Children 2012). AMBER Alerts are disseminated to radio and television stations, which then broadcast the information to their audience in the hopes of spreading the information as far as possible and increasing the chances of finding the child alive. This study will compare missing children stories from before and after the creation of this system.

Research Question 2: Does the representation of missing children stories differ from after the creation of the AMBER Alert system (1997-2011) compared to before that system (1987-1996)?

\section{METHODS}

This study utilizes a content analysis design, following the example of Min and Feaster's (2010) study. I analyze news broadcasts from CNN, NBC, ABC, CBS, and FOX News using the same search terms and variables as the previous study. I then compare my findings from the news broadcasts to the FBI's National Crime Information Center (NCIC) missing persons statistics for 2007-2010, the FBI's National Incident-Based Reporting System (NIBRS) for the years 1991-2010, and the National Incidence Studies of Missing, Abducted, Runaway, and Thrownaway Children (NISMART) from the Office of Juvenile Justice Delinquency and Prevention, which collected data from 1997-1999.

\section{Sample}

To generate the sample for this study, I used the Vanderbilt Television News Archive to find the population of all missing children stories from five news stations (CBS, CNN, NBC, ABC, and FOX News) from 1987-2011. The eight search terms used were: missing child(ren), 
missing boy(s), missing girl(s), and missing kid(s). After each of the eight searches, I created a list of all of the record numbers for each segment and compared all eight lists to search for and remove duplicates. I then read the short description of each segment to determine if it was relevant to the study. Any segment that referenced at least one missing child by name was included and any segments that did not reference a specific missing child were excluded from the population. Additionally, children who were missing as a result of a natural disaster were not included in order to match the sampling strategy by Min and Feaster (2010) as closely as possible $^{2}$.

After eliminating duplicates and irrelevant segments, the final population for all five stations from 1987-2011 was 619. In order to collect a sample that was large enough to be generalizable, but small enough to be feasible, I decided to separate the population into three groups (FOX News, all other stations Pre-AMBER Alert, and all other stations Post-AMBER Alert), and take a sample of 50 segments from each group.

The news stations were first divided into two groups: CBS, CNN, NBC, and ABC were combined into one group, and FOX News was left as its own group. It was divided in this way for two reasons. First, FOX News had the largest population out of all of the stations with 237 segments, even though the time period for this station only went back until 1997 (the station was only founded in 1996). The four other stations had a combined population of 386 for a longer time period, starting in 1987. I felt that it was important to oversample from FOX, since the original population was also larger.

The other reason for this division is based on the perceived political slant of each news station. According to a study conducted by the Pew Research Center (2009), most viewers (47\%)

\footnotetext{
${ }^{2}$ Min and Feaster (2010) did not include stories that involved Hurricane Katrina victims.
} 
considered FOX News to be mostly conservative, while roughly $30 \%$ of viewers saw the other stations as mostly liberal and $30 \%$ view them as neutral. In order to be able to compare representation of missing children stories by the perceived political orientation of the news station, the stations that were all viewed in similar ways were combined into one group, and FOX News was left separate because it was the only station viewed as having a particular political ideology.

After separating the news stations into two groups, the non-FOX group was then divided again into two time periods. Since the AMBER Alert system was implemented in 1996, I decided to define the Pre-AMBER Alert period as 1987-1996, and the Post-AMBER Alert period as 1997-2011. The FOX group could not be separated into two time periods because it was only founded in 1996.

After separating these three groups (FOX News, all others Pre-AMBER Alert, and all others Post-AMBER Alert), the segments were listed in chronological order, and a systematic random sample of 50 segments was taken from the Post-AMBER Alert non-FOX and the FOX group. The Pre-AMBER Alert non-FOX group only had 46 segments in that population, so instead of a random sample, that entire population was included.

\section{Levels of Analysis}

This study has two levels of analysis — reference level and individual-level — and while some variables will be the same in both analyses, other variables are unique to one or the other.

Reference-Level: Reference-level analysis refers to using each reference to a missing child across all segments as the unit of analysis. Some segments mention multiple children, and the segments in this sample had between one and six references. Each child mentioned in a 
segment is counted as a reference, and are counted each time regardless of the identity of the child being referenced. Therefore, one individual child may be counted multiple times in the reference-level analysis. This study has 208 references for this unit of analysis.

Individual-Level: Individual-level analysis refers to using each unique case as the unit of analysis. The name of each child mentioned in each segment is recorded, and each unique child is included in the individual-level analysis only once. This study has 118 cases for the individuallevel unit of analysis.

\section{VARIABLES}

Some variables in this study were gathered using the information in the segment abstract provided by the Vanderbilt Televisions News Archive, while others were coded by watching the news segment itself. Below is a description of each variable, grouped by the coding source (news segment or abstract).

\section{Variables Coded by Watching the Segment}

Name: The name of the child.

Race: The race of the child, based on the picture shown in the segment. Coded as White, Black, Latino/Hispanic, Asian, and Other.

Gender: The gender of the child, based on the picture shown in the segment. Coded as either Male or Female.

Age: The chronological age of the child at the time of his/her disappearance.

Situation of Disappearance: This variable pertains to the specifics of the case, with the situation types being Death, Kidnapping, Runaway, or Other/General Missing. Cases that 
potentially have overlapping situations (such as a kidnapping that ends in death) will be coded using the most serious situation. This variable was originally defined by Min and Feaster (2010).

Victim-Offender Relationship: The relationship of the suspect to the child. Coded as Stranger, Acquaintance/Friend, Relative/Family Member, or Not Applicable. Situations that are coded as a runaway or general missing will not have a victim-offender relationship.

\section{Variables Coded by Reading the Segment Abstract}

New Source: The news station that aired the segment: CBS, CNN, ABC, NBC, or FOX News.

Air Date and Time: The date and time that the segment aired on television. Provided by the Vanderbilt abstract. Inter-coder Reliability

Inter-coder reliability was conducted for race and gender to establish the credibility of visual coding from pictures shown in the news segment, as well as for age, situation of the disappearance, recovery, and victim-offender relationship. This inter-coder reliability was then also used for the individual-level data by making sure all of the variables matched for each child across all of the segments in which they appeared. Only cases in which inter-coder reliability was $100 \%$ were used in the analyses.

For cases in which the second coder and myself did not originally agree, I watched that particular segment again. If my judgment still did not match that of the second coder, that specific variable for that case was coded as a missing value. This allowed that case to be used for all of the other variables instead of eliminating the case completely. Below are results of this 
reliability test before eliminating variables in which agreement was not met, shown in percentage of agreement:

Age: $99.52 \%$

Race: $96.63 \%$

Gender: $99.52 \%$

Situation of Disappearance: $99.04 \%$

Victim-Offender Relationship: $85.10 \%$

\section{COMPARISON DATA}

There are three sources of comparison data that relate to this study: the FBI's National Crime Information Center's (NCIC) Missing Persons File, the FBI's National Incident-Based Reporting System (NIBRS), and the Office of Juvenile Delinquency and Prevention's National Incidence Studies of Missing, Abducted, Runaway, and Thrownaway Children (NISMART).

\section{National Crime Information Center (NCIC)}

The National Crime Information Center is maintained by the Criminal Justice Information Services (CJIS) Division of the Federal Bureau of Investigation. It is a clearinghouse of data associated with crimes (fugitives, stolen property, missing persons, etc.) that assists law enforcement agencies in their duties (FBI 2012a). This database currently has files for 19 different crimes, including a Missing Persons File ${ }^{3}$. While the actual database is not available to

\footnotetext{
${ }^{3}$ A description of the circumstances included in the NCIC Missing Persons File can be found on the FBI's website at: http://www.fbi.gov/about-us/cjis/ncic/ncic-missing-person-and-unidentified-person-statistics-for-2007.
} 
the public, the FBI provides summary tables on its website ${ }^{4}$. In order to mirror Min and Feaster's (2010) study as closely as possible, the analyses in this study will also use these summary tables.

However, there are a couple limitations of using the same tables as the previous authors. First, these files only provide aggregate totals by the race, gender, and age categories separately, but there is no way to determine any relationship between those variables. For example, there is no way to look at while female children under the age of 18; the files only show the number of female children, white children, and children under 18, all in separate columns. Second, the FBI's website currently only provides these tables for the years 2007-2012, and tables from 2006 are available upon request. I would like to be able to look at a longer time period to better analyze trends.

National Incident Based Reporting System (NIBRS)

One possible way to address these limitations to the NCIC data is by examining the FBI's National Incident Based Reporting System, or NIBRS. The NIBRS is a tool that law enforcement agencies use to submit crime information to the FBI and which includes details about each incident of crime that occurs in that agency's jurisdiction, including but not limited to: information about each incident, details about all of the offenses within each incident, victim information, offender information, arrest details, and other information about weapons, injuries, property damage, etc. (FBI 2012b).

One benefit of using this dataset over the NCIC files is that it gives much more detailed information about each incident. It allows examinations of relationships between variables, such

\footnotetext{
${ }^{4}$ The FBI's website currently provides the summary tables for 2007-2012. However, this study will use the tables for the years 2007-2011. See Footnote 1 for further explanation.
} 
as victim information, because the demographic characteristics of each victim are recorded. Another benefit is that this data is available for a longer time period, from 1991 to 2010.

However, this dataset also has some limitations. As described in the Frequently Asked Questions section of the FBI's website (FBI 2012b), the only offenses included in the NIBRS that would be relevant for this study are kidnapping and homicide. So although the media data include cases involving runaways and generally missing or lost children, the NIBRS data would be more limited for the situation of disappearance data.

Another limitation is that state participation in NIBRS reporting is not mandatory or complete. This means that there are some states that do not report any of this information to the FBI. According to the FBI's website, "as of 2007, 6,444 law enforcement agencies contributed NIBRS data" and "the data from those agencies represent 25 percent of the U.S. population" (FBI 2012b). Therefore, while this information is more detailed, it is not as representative as the NCIC data.

National Incidence Studies of Missing, Abducted, Runaway, and Thrownaway Children (NISMART)

Another possible source of comparison data is from the Office of Juvenile Justice and Delinquency Prevention: the National Incidence Studies of Missing, Abducted, Runaway, and Thrownaway Children, or NISMART. Instead of being a total count of crimes like the NCIC and NIBRS, the NISMART is a series of surveys (Sedlack et al. 2002). A household survey interviewed adults, and in some cases children, about any experiences involving a missing child, regardless of whether or not it was reported to the police. A survey of law enforcement focused on kidnapping cases by asking agencies about their stereotypical kidnapping cases. A third 
survey interviewed staff at juvenile facilities such as "juvenile detention centers, group homes, residential treatment centers, and runaway and homeless youth shelters" (Sedlack et al. 2002:2) to determine estimates about runaway and thrownaway children.

One of the major benefits of this data is that it includes situations that are not criminal in nature and are not reported to the police, as well as cases in which the children were not missing for any required amount of time. As long as the adult caretaker did not know the whereabouts of the child, even if the child was not actually lost or missing, those instances were included in this survey. Additionally, this survey sought to better understand youth runaways, which is often not included in discussions about missing children.

However, there are also major drawbacks about this data source as well. First, the data provided by this survey are presented similarly to the NCIC data, in that there are tables that represent each characteristic separately from one another, but do not address relationships between those characteristics. The report provides separate results based on race, gender, age, and situation, but not the relationship between race, gender, age, and situation.

Second, this report was conducted in 1999 and includes data from 1997-1999 (Sedlak et al. 2002). This only represents a small portion of the media data time period. There is also a previous version (NISMART 1) that was conducted in 1990 using data from 1988-1990 (Finkelhor, Hotaling, and Sedlak 1990), but the methods in that study are different from the second study, and the OJJDP states that the two surveys cannot be compared because of those differences (Sedlak et al. 2002). 


\section{ANALYSES AND RESULTS}

This study has three sets of analyses: comparing reference-level and individual-level media proportions to the three comparison data sources; comparing FOX News to the other news stations (as well as to the comparison data sources); and comparing the Pre- and Post-AMBER Alert time periods to each other (and to the comparison data sources). The results for Hypotheses 1-4 are reflected in Table 1 and are analyzed by comparing the reference-level media proportions and case-level media proportions to the appropriate comparison data sources. This depends on the structure of each comparison data source and the variables they contain.

The results for Research Question 1 are shown in Table 2 and are analyzed by comparing the proportions for each variable between station groups (FOX News and Other Stations). The proportions for the two station groups are also compared to the official data sources that apply to each variable.

The results for Research Question 2 are shown in Table 3 and are analyzed by comparing the proportions for each variable between time periods (Pre-AMBER Alert and Post-AMBER Alert). The proportions for the two time periods are also compared to the official data sources that apply to each variable. 
Table 1. Comparisons of Proportions by Unit of Analysis

\begin{tabular}{|c|c|c|c|c|c|}
\hline Variable/Sample Size & $\begin{array}{c}\text { Reference- } \\
\text { Level Media } \\
\text { Sample } \\
\end{array}$ & $\begin{array}{c}\text { Case-Level } \\
\text { Media } \\
\text { Sample } \\
\end{array}$ & NISMART & NIBRS & NCIC \\
\hline \multicolumn{6}{|l|}{ Situation } \\
\hline $\mathrm{n} / \mathrm{N}$ & 204 & 117 & 797,500 & 6,254 & $2,349,090$ \\
\hline Death & $22.1 \%^{\mathrm{B}}$ & $18.8 \%^{\mathrm{B}}$ & N/A & $10.2 \%$ & N/A \\
\hline Kidnapping & $62.3 \%^{\mathrm{A}, \mathrm{B}}$ & $59 \%{ }^{\mathrm{A}, \mathrm{B}}$ & $11.4 \%$ & $88.1 \%$ & $\mathrm{~N} / \mathrm{A}$ \\
\hline Runaway & $1.0 \%{ }^{\mathrm{A}}$ & $1.7 \%{ }^{\mathrm{A}}$ & $47.8 \%$ & N/A & $\mathrm{N} / \mathrm{A}$ \\
\hline General Missing & $14.7 \%{ }^{\mathrm{A}}$ & $20.5 \%^{\mathrm{A}}$ & $43.6 \%$ & N/A & $\mathrm{N} / \mathrm{A}$ \\
\hline \multicolumn{6}{|l|}{$\begin{array}{l}\text { Victim-Offender } \\
\text { Relationship }\end{array}$} \\
\hline $\mathrm{n} / \mathrm{N}$ & 111 & 72 & 797,500 & 6,254 & $2,349,090$ \\
\hline Non-Relative & $51.4 \%{ }^{\mathrm{A}, \mathrm{B}}$ & $44.4 \%{ }^{\mathrm{A}, \mathrm{B}}$ & $1.5 \%$ & $62.9 \%$ & $\mathrm{~N} / \mathrm{A}$ \\
\hline Relative & $19.8 \%{ }^{\mathrm{A}, \mathrm{B}}$ & $22.2 \%^{\mathrm{A}, \mathrm{B}}$ & $7.1 \%$ & $37.1 \%$ & $\mathrm{~N} / \mathrm{A}$ \\
\hline No Offender & $28.8 \%{ }^{\mathrm{A}}$ & $33.3 \%^{\mathrm{A}}$ & $95.3 \%$ & N/A & $\mathrm{N} / \mathrm{A}$ \\
\hline \multicolumn{6}{|l|}{ Race } \\
\hline $\mathrm{n} / \mathrm{N}$ & 186 & 118 & 797,500 & 6,254 & $2,349,090$ \\
\hline White & $88.4 \%^{\mathrm{A}, \mathrm{B}}$ & $80.5 \%{ }^{\mathrm{A}, \mathrm{B}}$ & $54.0 \%$ & $60.0 \%$ & N/A \\
\hline African-American & $7.0 \%{ }^{\mathrm{A}, \mathrm{B}}$ & $11.0 \%{ }^{\mathrm{A}, \mathrm{B}}$ & $18.8 \%$ & $34.2 \%$ & $\mathrm{~N} / \mathrm{A}$ \\
\hline Other & $5.1 \%{ }^{\mathrm{A}, \mathrm{B}}$ & $8.5 \%{ }^{\mathrm{A}, \mathrm{B}}$ & $27.2 \%$ & $1.7 \%$ & N/A \\
\hline African-American & $7.0 \%{ }^{\mathrm{C}}$ & $11.0 \%{ }^{\mathrm{C}}$ & N/A & N/A & $34.5 \%$ \\
\hline Not African-American & $93.0 \%{ }^{\mathrm{C}}$ & $89.0 \%{ }^{\mathrm{C}}$ & N/A & N/A & $63.3 \%$ \\
\hline \multicolumn{6}{|l|}{ Gender } \\
\hline $\mathrm{n} / \mathrm{N}$ & 205 & 118 & 797,500 & 6,254 & $2,349,090$ \\
\hline Male & $51.2 \%^{\mathrm{B}, \mathrm{C}}$ & $43.2 \%{ }^{\mathrm{A}}$ & $51.3 \%$ & $39.9 \%$ & $44.3 \%$ \\
\hline Female & $48.8 \%^{\mathrm{B}, \mathrm{C}}$ & $56.8 \%{ }^{\mathrm{A}}$ & $48.7 \%$ & $58.9 \%$ & $55.3 \%$ \\
\hline
\end{tabular}


Hypotheses 1 and 2 are analyzed by conducting a difference of proportions test using the NISMART and NIBRS proportions as expected values and comparing them to the situation and victim-offender relationship proportions of the missing child references in the media sample. The NCIC cannot be used for these analyses because it does not provide information on these variables.

Hypothesis 1, that kidnapping cases are over-represented in the media, found mixed results. This hypothesis was supported at both the reference-level and the case-level when compared to the NISMART, but varied between levels of analysis when compared to the NIBRS. When compared to the proportions from the NISMART, kidnapping cases are over-represented in the media at both the reference level $(\mathrm{z}=14.96, \mathrm{p}<0.001)$ and the case level $(z=10.42$, $p<0.001)$.

However, kidnapping cases are actually under-represented in the media at the reference level $(z=7.53, p<0.001)$ and the case level $(z=6.35, p<0.001)$ when compared to proportions from the NIBRS. However, since the NIBRS only contains information on two of the situation categories, these proportions may not align with the categories in the NISMART or the media sample, and comparisons for this variable to the NIBRS should be made cautiously. In sum, Hypothesis 1 was not supported because of conflicting results between comparison sources.

Hypothesis 2, which predicts that cases involving strangers are over-represented in the media, has similarly conflicting results. When compared to the proportions from the NISMART, cases involving strangers as suspects are over-represented in the media at both the reference level $(z=10.47, p<0.001)$ and the case level $(z=7.28, p<0.001)$. However, cases involving strangers are actually under-represented in the media at the reference level $(z=2.39, p=0.008)$ and the case level $(z=3.12, p<0.001)$ when compared to proportions from the NIBRS. 
The same issues apply here as in the previous analyses. The NIBRS only includes cases that involve both a victim and offender. Therefore, cases with no offender (such as runaways) are not represented in this data. Again, only cautious conclusions can be made based on these comparisons. Hypothesis 2 is not supported because of conflicting results between comparison sources.

Hypotheses 3 and 4 are analyzed by conducting a difference of proportions test using estimates from the NCIC, NISMART, and NCIC as the expected values and comparing them to the race and gender proportions of the missing child references in the media sample. For race, two different categories of race are used because of the differences in classification in the comparison data sources.

Hypothesis 3 is clearly supported at both the reference-level and case-level unit of analysis, and when compared to all three official data sources. African-American children are under-represented in the media at both the reference level $(z=14.61, p<0.001)$ and the case level $(z=7.24, p<0.001)$ when compared to NISMART, and also at the reference level $(z=11.67$, $p<0.001)$ and case level $(z=5.52, p<0.001)$ when compared to NIBRS.

For the comparisons using the NCIC, the categories of race are slightly different. The NCIC combines Hispanic and White into one category, so instead of using White as the comparison group, African-American is used instead, with all other races combined into the second category. Similar to the previous results, African-American children are underrepresented in the media at both the reference level $(z=14.66, p<0.001)$ and case level $(z=8.12$, $p<0.001$ ) when compared to the NCIC. Hypothesis 3 is supported; African-American missing children are significantly under-represented in the media when compared to official statistics. 
It is interesting to note that the NISMART reports different race proportions than the NIBRS and NCIC, which seem to be more similar to each other. For example, the NIBRS and NCIC report that about $34 \%$ of missing children are African-American, but according to the NISMART that proportion is only $18.8 \%$. Since the NIBRS and NCIC are both maintained by the FBI, it makes sense that they should have similar proportions. However, it is strange, and perhaps problematic, that the NISMART reports different proportions than the other two comparison data sources.

Similar to the race proportions, there is also a difference in gender proportions between the comparison data sources. The NISMART shows more missing children cases being males, whereas the NIBRS and NCIC show more female missing children. Therefore, Hypothesis 4 (predicting that female missing children are over-represented in the media) had conflicting results.

When compared to the proportions from the NISMART, female missing children cases are over-represented in the media at the case level $(z=1.77, p=0.04)$, but there was no significant difference at the reference level $(z=0.03, p=0.49)$. This pattern is actually reversed when compared to both the NIBRS and NCIC proportions. When compared to NIBRS, female missing children cases are under-represented in the media at the reference level $(z=2.84, p=0.002)$, with significant difference at the case level $(z=0.45, p=0.33)$. Additionally, when compared to the NCIC, female missing children cases are under-represented in the media at the reference level $(z=1.86, p=0.03)$, with no significant difference at the case level $(z=0.33, p=0.37)$. Since these results contradict each other, both at the level of analysis and between comparison groups, Hypothesis 4 is also not supported. 
Table 2. Comparisons of Proportions by Station Groups

\begin{tabular}{|c|c|c|c|c|c|}
\hline Variable/Sample Size & FOX News & $\begin{array}{c}\text { Other } \\
\text { Stations }\end{array}$ & NISMART & NIBRS & NCIC \\
\hline \multicolumn{6}{|l|}{ Situation } \\
\hline $\mathrm{n} / \mathrm{N}$ & 50 & 67 & 797,500 & 6,254 & $2,349,090$ \\
\hline Death & $4.0 \%^{\mathrm{B}, \mathrm{D}}$ & $22.4 \%^{\mathrm{B}}$ & $\mathrm{N} / \mathrm{A}$ & $10.2 \%$ & N/A \\
\hline Kidnapping & $64 \%{ }^{\mathrm{A}, \mathrm{B}}$ & $59.7 \%^{\mathrm{A}, \mathrm{B}}$ & $11.4 \%$ & $88.1 \%$ & N/A \\
\hline Runaway & $2.0 \%{ }^{\mathrm{A}}$ & $0.0 \%{ }^{\mathrm{A}}$ & $47.8 \%$ & N/A & $\mathrm{N} / \mathrm{A}$ \\
\hline General Missing & $30.0 \%{ }^{\mathrm{A}}$ & $17.9 \%^{\mathrm{A}}$ & $43.6 \%$ & N/A & N/A \\
\hline \multicolumn{6}{|l|}{$\begin{array}{l}\text { Victim-Offender } \\
\text { Relationship }\end{array}$} \\
\hline $\mathrm{n} / \mathrm{N}$ & 21 & 42 & 797,500 & 6,254 & $2,349,090$ \\
\hline Non-Relative & $14.3 \% \%^{\mathrm{B}, \mathrm{D}}$ & $59.5 \%{ }^{\mathrm{A}, \mathrm{B}}$ & $1.5 \%$ & $62.9 \%$ & N/A \\
\hline Relative & $9.5 \%^{\mathrm{B}}$ & $11.9 \%$ & $7.1 \%$ & $37.1 \%$ & $\mathrm{~N} / \mathrm{A}$ \\
\hline No Offender & $76.2 \%{ }^{\mathrm{A}, \mathrm{D}}$ & $28.6 \%{ }^{\mathrm{A}}$ & $95.3 \%$ & N/A & $\mathrm{N} / \mathrm{A}$ \\
\hline \multicolumn{6}{|l|}{ Race } \\
\hline $\mathrm{n} / \mathrm{N}$ & 46 & 62 & 797,500 & 6,254 & $2,349,090$ \\
\hline White & $87.5 \%{ }^{\mathrm{A}, \mathrm{B}}$ & $82.3 \%{ }^{\mathrm{A}, \mathrm{B}}$ & $54.0 \%$ & $60.0 \%$ & $\mathrm{~N} / \mathrm{A}$ \\
\hline African-American & $12.5 \%^{\mathrm{B}}$ & $8.1 \%{ }^{\mathrm{A}, \mathrm{B}}$ & $18.8 \%$ & $34.2 \%$ & $\mathrm{~N} / \mathrm{A}$ \\
\hline Other & $0.0 \%{ }^{\mathrm{A}, \mathrm{B}, \mathrm{D}}$ & $9.7 \%{ }^{\mathrm{A}, \mathrm{B}}$ & $27.2 \%$ & $1.7 \%$ & N/A \\
\hline African-American & $12.5 \%{ }^{\mathrm{C}}$ & $8.1 \%^{\mathrm{C}}$ & N/A & N/A & $34.5 \%$ \\
\hline Not African-American & $87.5 \%{ }^{\mathrm{C}}$ & $92 \%^{\mathrm{C}}$ & N/A & N/A & $63.3 \%$ \\
\hline \multicolumn{6}{|l|}{ Gender } \\
\hline $\mathrm{n} / \mathrm{N}$ & 46 & 62 & 797,500 & 6,254 & $2,349,090$ \\
\hline Male & $52.0 \%$ & $42.6 \%$ & $51.3 \%$ & $39.9 \%$ & $44.3 \%$ \\
\hline Female & $48.0 \%$ & $57.4 \%$ & $48.7 \%$ & $58.9 \%$ & $55.3 \%$ \\
\hline \multicolumn{6}{|c|}{${ }^{\mathrm{A}}$ The difference between the media proportion and the NISMART proportion is statistically significant at $\mathrm{p}=0.05$. } \\
\hline $\begin{array}{l}{ }^{\mathrm{B}} \text { The difference between the me } \\
{ }^{\mathrm{C}} \text { The difference between the me } \\
{ }^{\mathrm{D}} \text { The difference between the me }\end{array}$ & $\begin{array}{l}\text { proportion and th } \\
\text { a proportion and th } \\
\text { group proportion }\end{array}$ & $\begin{array}{l}\text { NIBRS propor } \\
\text { NCIC proporti } \\
\text { are statistically }\end{array}$ & $\begin{array}{l}n \text { is statistically si } \\
\text { is statistically sig } \\
\text { gnificant at } \mathrm{p}=0.0\end{array}$ & $\begin{array}{l}\text { nificant at } \mathrm{p} \\
\text { iificant at } \mathrm{p}=\end{array}$ & $\begin{array}{l}=0.05 \\
=0.05\end{array}$ \\
\hline
\end{tabular}


Research Question 1 asks: Do FOX News and the CNN, NBC, ABC, and CBS group differ in their coverage of missing children cases? This research question is analyzed by comparing the proportions in Hypotheses 1-4 (situation, victim-offender relationship, race, and gender) between the FOX News group and the non-FOX News group. This will allow us to see if there are differences not only between the media and comparison data sources, but also within the media. Only data from 1997-2011 was used for this analysis since FOX News did not exist before 1997. Additionally, only reference-level data was used so that there was no overlap of stations within each case. For example, one child/case may be referenced by multiple news sources, so the case-level data is not usable for this analysis.

FOX News reported significantly fewer references to situations involving death than did the group of other stations $(z=3.15, p<0.001)$, while the proportions for kidnapping, runaway, and general missing are not statistically different (see Table 2). Additionally, while FOX News significantly under-represented death cases when compared to the NIBRS $(z=2.19, p=0.014)$, the other stations actually over-represented those cases $(z=2.37, p=0.009)$. The representation for the other situations did not significantly differ between station groups.

FOX News reported significantly fewer cases involving strangers as suspects $(z=4.13$, $p<0.001)$ as well as cases involving no offender $(z=4.02, p<0.001)$ than did the other stations. The difference between the stations for cases involving relatives is not significant. While FOX News did not differ significantly from the NISMART proportions, the non-FOX News group significantly under-represented stranger cases $(z=7.57, p<0.001)$, and cases with no offender $(z=9.45, p<0.001)$.

The two media groups did not differ significantly in their proportions of White or African-American cases, and the representation for White and African-American was the same 
for both station groups when compared to both official data sources. However, FOX News reported fewer cases of Other Races than did the other stations $(z=2.56, p=0.005)$. Additionally, while the group of other stations did report more cases of other races, they still under-represented that race category when compared to the NISMART $(z=4.62, p<0.001)$, and yet over-represented that category when compared to the NIBRS $(z=2.11, p=0.018)$.

Similar to the previous analysis, there were no significant differences between stations for African-American or non-African-American race categories, but African-American cases were under-represented by both FOX News $(z=4.46, p<0.001)$ and the other stations group $(z=7.55, p<0.001)$ while all other races were over-represented by FOX News $(z=4.91, p<0.001)$ and the other stations $(z=8.26, p<0.001)$ when compared to the NCIC.

The comparisons for gender between station groups and compared to the official data sources are more complex than the others so far. While the differences between station groups are not statistically significant, FOX News reported more male cases than female cases, while the other stations reported more females than males. This is made even more complicated when comparing to the official data sources because they also have opposite proportions: while the NISMART reports that more male children were reported missing, the NIBRS and NCIC report that more females were reported missing.

As a general summary of the findings for Research Question 1, there were a couple differences in reporting based on news station. When compared to the other four news stations, FOX News reports significantly fewer cases involving death, more cases involving no offender, and fewer cases of children other than White or African-American. The two station groups do not differ significantly based on gender. 
Table 3. Comparisons of Proportions by Time Period

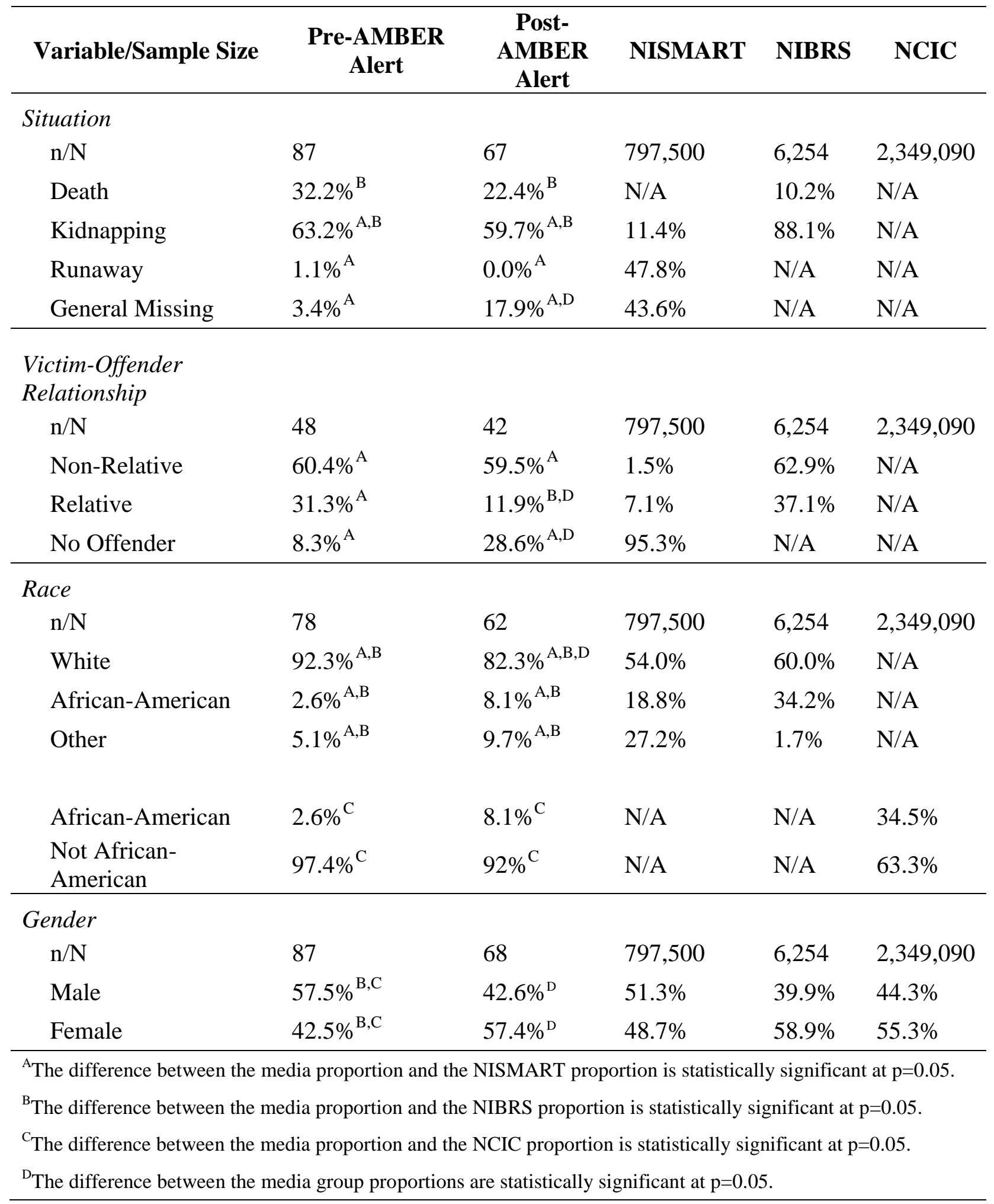


Research Question 2 asks: Does the representation of missing children stories differ from after the creation of the AMBER Alert system (1997-2011) compared to before that system (1987-1996)? Similar to the analyses comparing station groups, Research Question 2 was analyzed by comparing the proportions for situation, victim-offender relationship, race, and gender for the non-FOX News group from before (1987-1996) and after (1997-2011) the AMBER Alert system to see if the media shifted their representation of missing children cases over time. The FOX News group was not included for these analyses because it only existed during the post-AMBER time period.

Before examining the results of these comparisons, it is interesting to first examine the general trend in reporting missing children cases based on total segments before and after the AMBER Alert. For example, when looking at the study's original population (before the sample was taken), all four news stations show an increase in segments that mentioned a missing child after the AMBER Alert compared to before, with CNN showing the greatest increase (see Figure 1), while the total number of segments in the population across all four stations increased from 46 to 573 . This shows that there was a large increase in news segments about missing children after the implementation of the AMBER Alert system in 1996. 
Figure 1. Total Segments per Station in Original Population: Pre- and Post-AMBER Alert

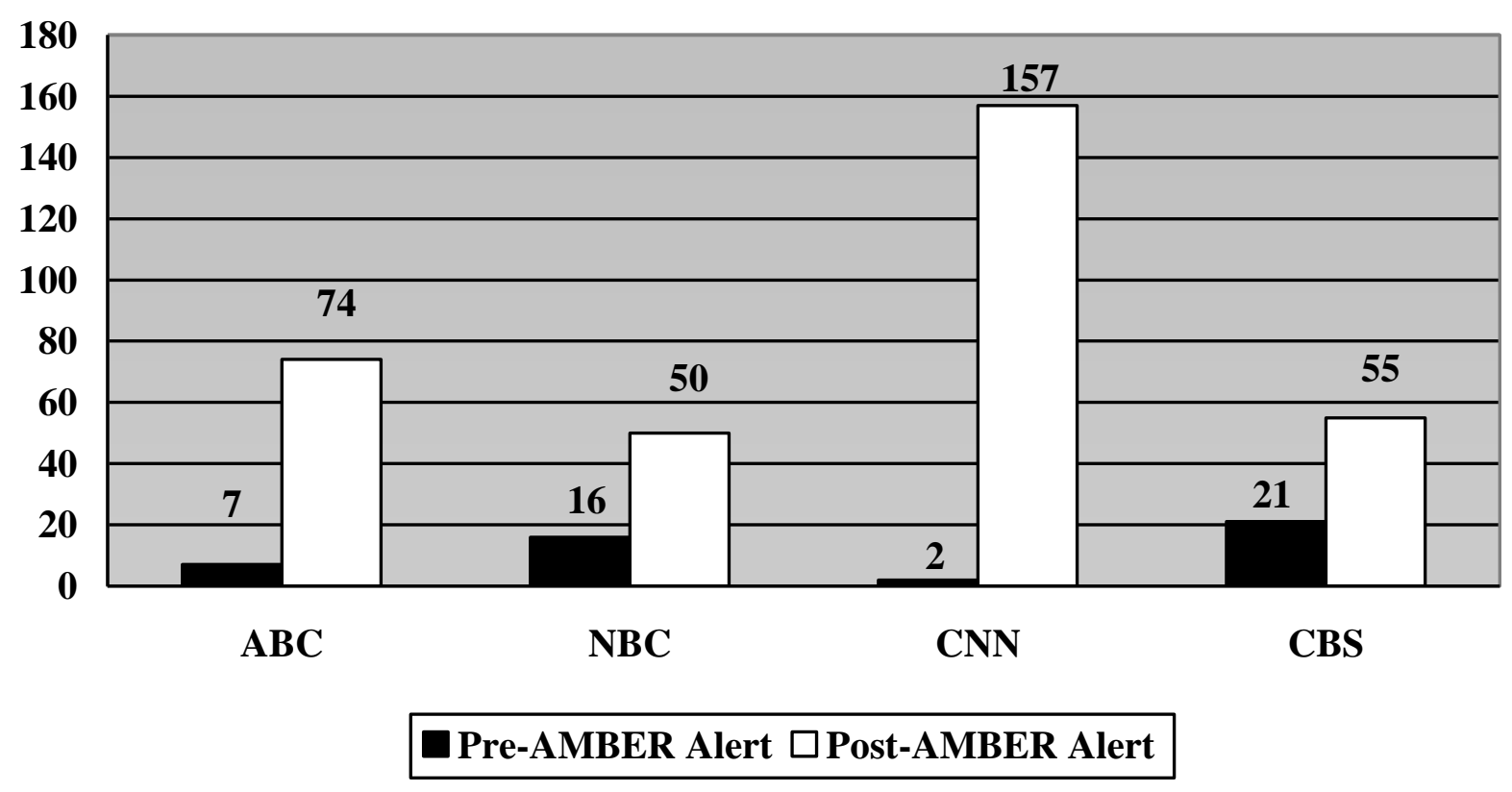

There were also some differences in representation for some variables between the time periods. One interesting result is that the other news stations (excluding FOX News) significantly increased their coverage of general missing cases $(z=2.84, p=0.002)$. These tend to be cases where the child gets lost (but did not run away) and there is no actual crime or offender. However, while the only difference between time periods is with the general missing situation, both time periods differed significantly from both the NISMART and NIBRS in their coverage of all four situation categories (see Table 3).

Going along with the increase in general missing cases, the non-FOX News station group also show an increase in reporting cases that involve no offender $(z=2.50, p=0.006)$, which coincides with a decrease in coverage of cases involving relatives as the offender $(z=2.30$, $p=0.011$ ). Coverage of cases with non-relative offenders has remained about the same.

When compared to the NIBRS, the Post-AMBER Alert period had a significantly lower amount of references to stranger cases $(z=7.56, p<0.001)$, but none of the other comparisons 
were significant. However, when compared to the NISMART, the Pre-AMBER Alert period shows a significant over-representation of stranger cases $(z=8.26, p<0.001)$, an overrepresentation of cases involving a relative as the offender $(z=3.58, p=0.0002)$, and an underrepresentation of cases with no offender $(z=21.62, p<0.001)$.

The Post-AMBER Alert period also shows a significant over-representation of stranger cases $(z=7.75, p<0.001)$ and an under-representation of cases with no offender $(z=9.45, p<0.001)$. Additionally, the comparison data sources also differ for this variable. So while the station groups may over-represent a certain relationship compared to the NISMART, it is an underrepresentation when compared to the NIBRS.

As shown in Table 3, the non-FOX News station group decreased their coverage of missing White children after the implementation of the AMBER Alert system $(z=1.74, p=0.04)$, while slightly increasing their coverage of missing African-American children $(z=1.40, p=0.08)$. The change in coverage for children of other races is not significant.

When analyzing race differences using the NCIC categories, coverage of AfricanAmerican children increase $(z=1.40, p=0.08)$ and coverage of non-African-American children decrease slightly $(z=1.38, p=0.08)$. Compared to the NCIC however, African-American cases were under-represented and non-African-American cases were over-represented in both time periods (see Table 3).

Similar to the gender proportions comparing station groups, the proportions between the time periods were also reversed. During the pre-AMBER Alert time period, males are shown more often while females are shown more during the post-AMBER Alert period $(z=1.85$, $p=0.03)$. 
As a general summary of the findings for Research Question 2, there are also some differences in reporting based on time period. When compared to the pre-AMBER Alert time period, during the post-AMBER Alert time period the non-FOX News station group increased their reporting of general missing children cases and decreased cases involving death, increased reporting of cases involving no offender while decreasing cases involving relatives as the offender, and slightly decreased cases involving White children while increasing cases involving African-American children. It is interesting to note that while gender representation does not differ between the station groups, over time the proportion of coverage of male cases significantly decrease, while coverage of females increase during the post-AMBER Alert time period.

\section{DISCUSSION AND CONCLUSION}

There are several contributions of this study. First of all, it replicates a previous study (Min and Feaster 2010) and gives credibility to the reliability of their methods, but also challenges their unit of analysis and comparison data source. It extends that previous study by looking at different variables, units of analysis, and comparison data sources. It also contributes to the literature on race and gender in the media, and connects those two areas in the context of missing children. This study also provides directions for future research by examining some of the limitations of both this study and the Min and Feaster (2010) study.

One purpose of this study was to replicate the Min and Feaster (2010) study, with the goal of finding similar results in order to support the reliability of their study. This goal was met with success after finding similar results for race and gender. However, another goal was to 
explore the validity of that study by addressing the unit of analysis and the comparison data source.

In terms of the unit of analysis, the reference-level that Min and Feaster (2010) used was still a valid approach, but I believe comparing it to a case-level unit of analysis yields interesting and important results. For example, the gender results of this study matched those of Min and Feaster (2010) when only looking at the unit of analysis that they used, but they became more complex and contradictory when compared to case-level data. While reference-level data allows more flexibility for comparisons between news stations and between time periods, a case-level approach helps to control for over-counting if a particular child shows up in the sample more than once.

Another important contribution of this study is the finding that the "official" data sources all differed from each other. This is important because the major premise to this research is to compare media representations with national statistics, but if there are multiple data sources, and they all report different proportions, then that limits the conclusions that can be drawn about the media's accuracy. Unless a consensus can be reached about which data source is the most accurate, then comparisons between the media and official statistics will lead to conflicting results based on the data source chosen. Future studies could delve further into this issue of differences in official statistics and perhaps provide an explanation for those differences.

\section{Limitations and Directions for Future Research}

There are other issues of validity with regard to the comparison data sources. The NISMART is a phone survey that utilizes a sample. This methodology may neglect those families who do not have phones, and while the sample was ideally random, that is not 
guaranteed. In addition, since I was attempting to examine the differences in media proportions and reported statistics, I chose to only use the figures in the "Reported Missing" section of the NISMART as opposed to the "Caretaker Missing" information. Caretaker Missing refers to instances when a respondent did not know the location of the child, but did not report it to police. Hence, that child was missing from the caretaker, but had not been reported missing. However, future studies may delve further into the Caretaker Missing data to see what differences there may be in what people say actually happened, and what they reported to police.

The FBI data also has some issues. One issue deals with representativeness of the data. The NCIC is a tool that is available for law enforcement to use, but submission of information to the database is not required. Additionally, at present only 36 states submit complete data to the NIBRS, so that may also not be representative of the entire United States population.

The second issue relates to the quality of the data. These two data sources are just repositories for state and local law enforcement data. This means that the FBI is not the agency collecting this information; the state and local law enforcement agencies collect the information and submit it to the FBI. This can lead to issues of data quality. The FBI conducts audits of agencies to ensure uniform reporting practices that match the FBI's definitions, but it is possible that some agencies may still interpret cases differently or report inaccurate information.

Future studies should consider different sources of comparison data in order to try to offset these limitations. Different federal agencies collect crime information or conduct surveys, and many of them may differ from each other in their methodologies and results. Future studies should also look more closely at the process of what happens from when a crime is reported to police to when it is published as a statistic. As stated before, if different agencies are reporting information to one central data repository, it is important to understand the process that occurs 
during the transformation and interpretation, especially where definitions or statutes may be different.

While this study provides some insight into the representation of missing children in national television news, it does not address possible avenues that under-represented groups may take to increase their media presences and gain media coverage for their cases. It also does not examine the more qualitative issues such as the word choice, tone, or framing of news segments, which could be another venture for future research. The issue of missing children in the media could be approached in a variety of ways, from multiple theories and using multiple methodologies. This study could serve as a road map for missing information and unexplored questions in this area of study. 


\section{REFERENCES}

Best, Joel. 1990. Threatened Children: Rhetoric and Concern about Child-Victims. Chicago: The University of Chicago Press.

Chiricos, Ted, Sarah Eschholz, and Marc Gertz. 1997. "Crime, News and Fear of Crime: Toward an Identification of Audience Effects." Social Problems 44(3): 342-357.

FBI. 2012a. "National Crime Information Center.” Accessed November 3, 2012. <http://www.fbi.gov/about-us/cjis/ncic>.

FBI. 2012b. "NIBRS General FAQs.” Accessed November 3, 2012. < http://www.fbi.gov/aboutus/cjis/ucr/frequently-asked-questions/nibrs_faqs>.

Finkelhor, David, Gerald Hotaling, and Andrea Sedlak. Office of Juvenile Justice and Delinquency Prevention. 1990. “First Report: Numbers and Characteristics, National Incidence Studies." Missing, Abducted, Runaway, and Thrownaway Children in America i-379.

Fritz, Noah J. and David L. Altheide. 1987. "The Mass Media and the Social Construction of the Missing Children Problem.” The Sociological Quarterly 28(4): 473-492.

Glassner, Barry. 1999. The Culture of Fear: Why Americans Are Afraid of the Wrong Things. Basic Books: New York, NY.

Griffin, Timothy and Monica K. Miller. 2008. "Child Abduction, AMBER Alert, and Crime Control Theater." Criminal Justice Review 33(2): 159-176.

Herman, Edward S. and Noam Chomsky. 1988. “A Propaganda Model.” Pp. 1-35 in Manufacturing Consent: The Political Economy of the Mass Media. New York, NY: Pantheon Books. 
Kellner, Douglas. 1981. "Network Television and American Society: Introduction to a Critical Theory of Television." Theory and Society 10(1): 31-62.

Liebler, Carol M. 2010. "Me(di)a Culpa?: The 'Missing White Woman Syndrome' and Media Self-Critique." Communication, Culture and Critique 3: 549-565.

Miles, Thomas J. 2005. 'Estimating the Effect of America's Most Wanted: A Duration Analysis of Wanted Fugitives.” Journal of Law and Economics 48(1): 281-306.

Min, Seong-Jae and John C. Feaster. 2010. "Missing Children in National News Coverage: Racial and Gender Representations of Missing Children Cases." Communication Research Reports 27(3): 207-216.

National Center for Missing and Exploited Children. 2012. "FAQ: AMBER Alert." Retrieved September 30, 2012.

<http://www.missingkids.com/missingkids/servlet/PageServlet?LanguageCountry=en_U S\&PageId=2813>.

Pew Research Center. 2009. "How the Public Judges News Network Ideology.” Pew Research Center Publications. Retrieved March 22, 2012. <http://pewresearch.org/pubs/1394/foxnews-viewed-as-most-ideological-network>.

Pew Research Center. 2010. "Ideological News Sources: Who Watches and Why.” Pew Research Center: iv-141.

Sedlack, Andrea J., David Finkelhor, Heather Hammer, and Dana J. Schultz. Office of Juvenile Justice and Delinquency Prevention. 2002. "National Estimates of Children: An Overview." NISMART: National Incidence Studies of Missing, Abducted, Runaway, and Thrownaway Children 1-12. 
Sommers, Samuel R., Even P. Apfelbaum, Kristin N. Dukes, Negin Toosi, and Elsie J. Wang. 2006. "Race and Media Coverage of Hurricane Katrina: Analysis, Implications, and Future Research Questions." Analyses of Social Issues and Public Policy 6(1): 39-55.

Wilson, Barbara J., Nicole Martins, and Amy L. Marske. 2005. "Children's and Parents' Fright Reactions to Kidnapping Stories in the News." Communication Monographs 72(1): 4670. 